\title{
Can we continue to recycle our brackets in 2008?
}

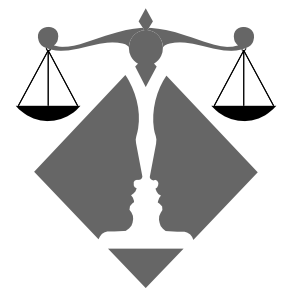

\author{
F. BONNIN
}

\begin{abstract}
The recycling of orthodontic attachments is a controversial practice both in its technical application and in its legal aspects. The number of orthodontists using this method varies widely from country to country. Because laws applying to attachment recycling in France and throughout the European union have changed recently, we believe this is an appropriate time to review the legal ramifications of the procedure.
\end{abstract}

\section{KEYWORDS}

Orthodontic attachment

Recycling

Legislation

Ethics. 


\section{1 - INTRODUCTION}

Are there still any orthodontists who recycle their brackets? While this question may seem incongruous to many practitioners, it certainly appears to be a practice that retains at least a modicum of appeal if we judge by the number of solicitations orthodontists regularly receive from enterprises offering to recycle their used attachments. If it is not exactly a common practice, it is nevertheless popular enough to keep three distinct commercial purveyors of this service in business: and in our judgment hundreds of thousands of orthodontic attachments are recycled every year in France. Confronted with the exasperation of our suppliers who claim to have the best interests of the profession at heart, we should seize this moment to review the legal aspects ${ }^{1}$ of a controversial procedure whose applications have a clear impact on a variety of groups with widely divergent interests.

\section{2 - EUROPEAN LAW}

\section{2 - 1 - Directive 93/42 CEE}

The European market for medical devices is the second largest in the world after the American and more substantial than the Japanese. It represents $30 \%$ of world-wide sales at an estimated value of 54.8 billion euros (source Eucomed Industry Profile 2003) and employs 385, 000 people, a good indication of its importance. Because of its stature, Europe has issued three directives to control this giant market:

- directive 93/42/CEE that deals with medical devices (DDM);
The different words they employ to describe the same technique, recycling for some, re-use for others, and "good as new" for still others all betray the uneasiness of the participants in establishing their bone fides.

The issue then is not the efficacy of the recycling technique ${ }^{2}$ but its standing in jurisprudence or, more to the point, the best case that can be made, from every point of view, for its being legal.

And another more subjective factor cannot be left unexamined and that is the ethical problem: apart from the legality or the illegality of the technique can we accept in good conscience the re-use of medical devices whose manufacturers have not constructed them with this in mind?

- directive 90/385/CEE that deals with implants (DDMIA);

- directive 98/79/CE that deals with diagnostic tools used on patients.

As far as orthodontics is concerned, the applicable reference text is directive 93/42, which deals with the sale of new devices. The medical appliances are divided into four categories that correspond, in ascending order, to the risk associated with them. Orthodontic devices are included in Class I and Class Ila.

This directive describes the quality control procedures that are a require- 
ment for obtaining the $\mathrm{EC}$ marking that is needed for the sale of any medical device. Starting with Class II, manufacturers are strongly advised to have promulgated a quality assurance protocol that can be awarded the ISO 13485 certification. They must establish a EC declaration of conformity after having shown proof that the device in question satisfies the essential requirements of guaranteeing the security and health of patients in compliance with the applicable directive.

For medical devices in the Class II a, $\| \mathrm{b}$, and III categories, the manufacturer submits a control of organism notification (these organisms are listed by the official Journal of the European Community, the OJEC).

The manufacturer selects the type of proof, as defined in the directive, that is the most appropriate for the class of the device and its individual characteristics with regard to the way it is made and the system of quality assurance devised for it. These controls deal with both conception and fabrication of the device. Manufacturers are required to reevaluate their products regularly in accordance with the selected procedure.

In conclusion, the 93/42 directive constrains manufacturers to follow a rigorous manufacturing procedure and quality control set-up before introducing any products for sale in the market place; but they are left free to decide that any given device should be employed on a use once and throw away basis or, instead, be

(1) http://www.europarl.europa.eu/sides/getDoc.do? pubRef = -//EP//TEXT + REPO RT + A5-2003-0125+ 0+DOC+XML+V0//FR\#title2 re-cyclable, which means that that a "legal gray area" has been left about this issue.

\section{2 - 2 - Changes in the directive}

In 2003 the Minerva Malliori report (1) asked for a revision of the directive, emphasizing the gaps in the 1993 text which regulated only the introduction of a product without dealing in any way with its possible eventual re-use, which opened the door to the current system where manufacturers do whatever seems best to them. The author of the report was categorically opposed to any re-use of devices and envisioned the installation of uniform legislation in every state in the union in order avoid the confusion of devices being utilized only once in some areas and being recycled in others.

"The 93/42/CEE directive dealing with medical devices didn't not actually control the use of devices nor with the re-treatment of devices designed for a single use. It merely regulated the introduction to the market place of a new product and the uses to which it could be put, the ones, in fact, for which it was designed.

Manufacturers were charged with guaranteeing the security of the product and alone had the responsibility for showing that the device was risk free when used in accordance with adequate procedures and quality control techniques with homogenous lots. Measures needed to be taken to insure that devices designed for a single use were not employed for a second time."

Madame Malliori concluded her report with this statement, "The re- 
employment of medical devices designed for a single use constitutes a risk for patients and hospital personnel. Therefore studies and research dealing with this issue should be encouraged so that member States can take the necessary measures for insuring that any such re-utilization does not take place."

\section{2 - 3 - The 2007/47/CE Directive} (2)

Adopted on September 5 2007, this directive is the fruit of five years of work following the revelations of the inadequacy of the preceding directive, shown in the Malliori report. The following new points were enunciated:

- re-use of medical devices is a reality; it should not be allowed to affect the safety of the health of patients.

"Consideration 7: it is important that security measures be taken to insure that the re-use of medical devices does not put the safety or the health of patients in danger. It is deemed necessary, from this time on, to clarify the definition of the phrase "single use" in all of its possible ramifications as well as to formalize the requirement for uniform labeling and instructions for use. In addition, the Commission should make an in depth analysis for the determination of the possible need to take additional measure for guaranteeing a high level of protection for patients."

(2) www.unamec.be/data/doc/2007-47-CE\%20dispositifs \%20medicaux\%20et\%20biocides.pdf -
- The directive must be applied in the same way throughout the Union in harmony with the principles of subsidiarity.

"The member States should take appropriate measures so that the competent authorities of these member States cooperate with each other and with the Commission, and communicate all necessary information required for a uniform application of this present directive.

In order to coordinate the uniform application of this present directive, the Commission is organizing exchanges of experiences between the competent authorities in charge of overseeing the market place.

Without any pre-conditions or prejudices with regard to this present directive, this cooperation can be inscribed in the framework of initiatives put in place on an international scale."

- A definition of the phrase "single use" does, in fact, exist:

"A single use device: a device designed to be used a single time for one patient only."

- A session planned for September 52010 will prepare legislation especially focused on re-use of medical devices: a study of the impact of this decree will be carried out in 2008 and 2009 so that hard facts will reenforce the legislation of 2010:

"Re-use of medical devices: on no later than the $5^{\text {th }}$ of September 2010, the Commission will present a report on the contentious issue of re-use of medical devices in the European Community to the European Parliament and to the Council." 
In the light of the conclusions presented in this report, the Commission will submit to the European Parliament and to the Council any supplementary propositions that it judges appropriate to the goal of guaranteeing a high level of protection for the health of the public."

- Manufacturers must precisely state in their labeling "single use only" so as to avoid abusive practices by purchasers:

"If the device carries a label specifying that the product is designed for a single use only, manufacturer's information should be included about the known characteristics and technical factors that could

\section{3 - THE FRENCH LAW}

It must be remembered that a European directive constitutes an unchangeable base level regulation corresponding to minimum requirements, even if it should rank high on the normal curve, because national law can redefine it, but never "soften" it. Accordingly each member state can "harden" the directive in any way it sees fit, through circulars, additional regulations, decrees, etc., but not reduce its impact.

Germany, for example, has decided to abide to the first directive of 93 strictly but will not be able to disregard the new rules in two years. France has opted from the beginning for a strengthening of the European text because the directive already went beyond the texts then in force through the 1986 circular. present a risk if the device has to be employed again. If, in conformity with point 13.1, no utilization notice is necessary, information must be provided to the practitioner upon request."

It is, therefore, to be expected that in the next two years manufacturers of orthodontic attachments are going to justify the composition of their products in terms of the alloys utilized and in regard to the risks of corrosion or deformation of attachments inherent in the recycling process. The Commission will certainly take all necessary measures to "guarantee the maintenance of protection of patients at a high level."

\section{3 - 1 - Circular DGS/SQ3, DGS/ PH2, DH/EM1 $\mathrm{n}^{\circ} 51$ of 29 December 1994 (3)}

This circular replaces that of 1986 (DGS/DH/DPHM n 669 of 14/04/ 1986) which promulgated the rule forbidding the re-employment of any material or device designed for a single use.

In this document risks are described as a function of the nature of the device or usage:

- risks related to the devices themselves;

- risks related to clinical use;

- risks related to recycling.

(3) www.hosmat.eu/circulaires/textes94/51.html 
It is clear that in the area that most concerns us, non-measurable changes in a device, primarily in its physical properties, the condition of its surface, and its mechanical characteristics should all be considered.

\section{3 - 2 - Circular DGS/VS2-DH/EM1/ EO1 $\mathrm{n}^{\circ}$ 97-672 of October 201997 (4)}

This circular deals with sterilization of medical devices in public health care settings, describing in detail the establishment of on-site quality controlled sterilization systems. It does not, therefore, directly affect private practitioners working in their individual offices.

\section{3 - 3 - Decree n ${ }^{\circ}$ 2005-840 of July 202005}

This decree, whose useful text on regulations in the code for public health (Article R. 6111-19) clearly states that medical devices designed for one time only employment should not be re-used.

These preceding circulars which public officials used as a basis in 1998 for undertaking legal action against cardiologists and certain health care facilities (TGI Paris $16^{\text {th }}$ chamber - judgment of 23/09/1998) did not have the force law and as a result the judgment was reversed on appeal.

The Appeals Court of Montpellier (Judgment $n^{\circ} 566$ of 28/03/2000) which reversed the Nîmes decision based its ruling on the character of the circulars, which had the status of recommendation and were not regulatory. This would certainly no longer be the case in view of the judicial character of this latest decree.

the risks of transmission of pathogenic agents in any way.

This national legislation was never in conflict with European regulations that themselves did not refer to recycling until last September. But France, on the other hand, has for a number of years been completely opposed to the position taken by Germany, which, nevertheless, remains its principal European partner.

The new directive, while imprecise, will for two more years affirm the principle that re-cycling of medical devices should conform to regulations

(4) http://www.sante.gouv.fr/htm/pointsur/nosoco/ nosoco3-2-672.html 
regarding single or multiple use that are harmonious or similar in all the member states of the European Union.

And there is every reason to believe that Europe will establish its position in 2010 at the level expressed by the country with highest standards for health and security, which is France.

\section{4 - 2 - Aspects of dental regulations and code of ethics}

The first section of the code of ethics that details with general obligations of dentists has only one article that requires our attention.

Art. 4127-204: Dentists should never practice their profession in conditions that could compromise the quality of care offered or adversely affect the well being of their patients. They must at all times take every precaution to prevent the transmission of any type of pathology or pathological agent and assure that all their associates and assistants work to the same end.

The code of ethics and good dental practice insists that strict antiseptic rules be observed at all times, that the overall quality of care be as elevated as possible, and that excellence of the materials employed be at the highest level. This means that employing nonconforming or defective materials is a violation of the ethical code.

We should, in addition, bear in mind these aspects of re-cycling. Orthodontists sending attachments out for re-cycling do it only for economic reasons, to reduce the need for purchasing expensive new materials and thus lowering their over-all costs We do not re-cycle attachments in our office, considering it to be a shoddy practice, whose goal is to achieve a better profit margin than would be possible with the exclusive use of new attachments.

This is my personal opinion, one that I admit could be tempered by two arguments:

- some practitioners can command only relatively low fees because of poor economic conditions in their region;

- orthodontists have to pay for the considerable savings in treatment that they can reap with the new selfligating brackets by paying their purchase costs that are five to ten times higher than those of traditional brackets. So fees, which are indexed on duration of treatment, will in the future have to take into consideration the considerable increase in the expense item "purchase of materials."

Let us step back from the judicial, that is to say the legal framework, to reflect for a moment on the ethical aspect of the matter. The issue of recycling can be resolved in only one way: in accordance with the doctrine of informed consent we should inform our patients of the reduced fees they can obtain if they choose treatment with re-cycled attachments.

As Papadopoulos ${ }^{3}$, has affirmed, patients want high quality treatment, which implicitly would include the use of new materials for their appliances. Patients, not to mention their parents, would be severely disconcerted should they learn that the braces in their mouths had previously been installed on some one else's teeth, even if these attachments had been recycled and carefully sterilized. These 
negative reactions would be based on deeply embedded psychological factors. They might however be more accepting of the procedure if they knew it meant a considerable deduc- tion in fee. In any case, families themselves should make the decision in conformance with the principles of informed consent.

\section{5 - CONCLUSION}

We can easily answer the question we posed at the outset: French law prohibits the recycling of orthodontic attachment in the framework of the requirement that no medical device be used more than once, which has been in force for twenty years. This very clear position may appear simplistic in relation to the complexity of the stakes involved. But at the very least it allows public authorities to insist that there be no impairment of the sacrosanct principle of precaution. The European community has been relatively slow to become aware of the gaps in the 1993 directive. The preparatory work for its restructuring have been completed except in the area that particularly interests us; the Community has very recently revised its directive but it still allows a two year delay for the installation of a statute on the question of re-use of devices with the double goal of harmonizing the practices of all the member states and of assuring a high level of public health.

French law in this regard, however, has become more strict, as the 2005840 decree no longer has the quality of only a recommendation as was the case with previous circulars but now has the status of a regulation. Is that desirable? Some observers are not sure pointing out that the manufacturer is perfectly free to add the label "single use only" with great ease as sales increase. That is why there is a need to ask manufacturers to justify their decisions quite seriously. There is, accordingly, a good complimentary relation between the very new directive 2007/ 47/CE and the new decree 2005-840.

The judicial problem will be definitively settled in 2010 and it will not be necessary to wait for an authorization from the European community for the question of the recycling of orthodontic attachments.

We have, in addition, brought up the principle of precaution: can orthodontists free themselves from it? Let us not forget that recycling remains technically at least a risky undertaken because no method has universal approval nor the exclusive support of manufacturers. It would seem that all methods cause dimensional change in the bracket slot and a reduced capacity to adhere to the enamel surface of teeth.

So that it is clear that recycled attachments are above all an issue that concerns the ethical standards of individual practitioners. The proedure is not only quasi-illegal, it seems to be unsupported by a good scientific consensus. It could said to be unethical because it might compromise the quality of care. 
And, finally, the practice falls even further outside the range of honorable practice when practitioners use it without informing their patients.

It seems to us urgently important for practitioners who are recycling brackets without being completely familiar with the latest legislation on the topic to inform themselves thoroughly and to carefully re-evaluate their responsibilities not only before the law but also ethically.

\section{REFERENCES}

1. Bonnin F. La réutilisation des dispositifs médicaux a usage unique: a propos des attaches orthodontiques. Mémoire de Master II pro Droit de la Santé parcours «Droit de I'expertise appliqué a I'odontostomatologie». Paris: Univ Paris 8, 2008.

2. Muller M. Impacts des traitements chimiques, thermiques, électrolytiques et au laser, sur les propriétés dimensionnelles, structurelles et fonctionnelles des attaches orthodontiques. Rev Orthop Dento Faciale 2000;34:477-86.

3. Papadopoulos M.A. Le recyclage des attaches orthodontiques: effets sur leurs caractéristiques et leurs propriétés physiques - aspects éthiques et juridiques. Rev Orthop Dento Faciale 2000;34:257-76. 